\title{
A Rare Case of Colorectal Injury With Compressed Air
}

\author{
Mehmet Ergin a, b, Muhammed Rasit Ozer ${ }^{\mathrm{a}}$, Sedat Kocak ${ }^{\mathrm{a}}$, Nazli Karakus ${ }^{\mathrm{a}}$, \\ Betul Babagila ${ }^{\text {, Basar Cander }}{ }^{\mathrm{a}}$
}

\begin{abstract}
Colorectal injures from implement on solid objects are infrequent but not rare. In the same category are injuries caused by non solid objects. Barotrauma from compressed air and liquid is less frequently encountered. In this report, you can read a case with colorectal injury after using air hose to dust off patient's clothing. Although taking history sometimes is not possible due to factors related with patients' condition, physical and radiological findings related with tension pneumoperitoneum can make physician diagnose injury and etiology.
\end{abstract}

Keywords: Colorectal injury; Compressed air; Pneumoperitoneum

\section{Introduction}

Colorectal injures from implement on solid objects are infrequent but not rare. In the same category are injuries caused by non-solid objects. Barotrauma from compressed air and liquid is less frequently encountered [1]. We are presenting a case of barotrauma to the colon from compressed air and discuss diagnosis, injury patterns and treatment of this type of injury.

\section{Case Report}

A 36-year-old man was admitted to ED due to his abdominal pain and distension after using air hose to dust off his clothing. His vital signs were in normal range and physical exam was normal except abdominal distension and signs of peri-

Manuscript accepted for publication November 16, 2012

\footnotetext{
${ }^{a}$ Necmettin Erbakan University, Meram Medicine Faculty Emergency Medicine Department, Turkey

${ }^{\mathrm{b}}$ Corresponding author: Mehmet Ergin, Necmettin Erbakan

Universitesi Meram Tip Fakultesi Acil Tip AD, Meram, Konya,

Turkey. Email: drmehmetergin@gmail.com
}

doi: http://dx.doi.org/10.4021/jmc997w toneal inflammation. His chest and abdomen- $\mathrm{X}$ ray showed huge amount of pneumoperitoneum (Fig. 1). His intraoperative findings were free intraperitoneal air without free fluid and bowel contents, dilated colonic segments, multiple serosa injuries in all segments of colon but especially sigmoid colon and cecum. There was neither perforation finding in the colon nor any other abdominal organ injury. His followup period was completed without any complication and he was discharged in the 5th day after operation.

\section{Discussion}

Review of the literature reveals a similar case report in 1904 from a British surgeon in London [2]. Case analysis of pressurized-air injuries often reveal a misguided coworker and unwise behavior. Those cases not involving misbehavior usually occurred when employees used an air hose to dust off their clothing as likewise in our case. It is important to realize that this injury can occur without inserting the air hose into the anus $[1,2]$. In several cases reported in the literature,

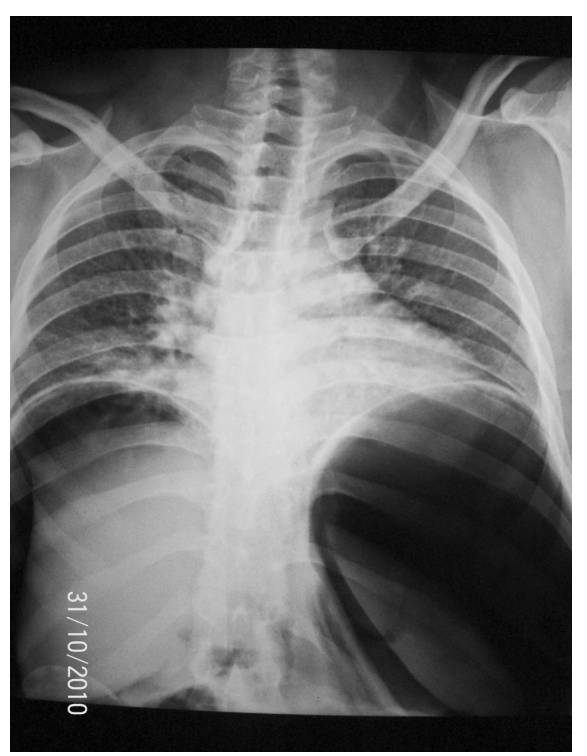

Figure 1. Abdominal $\mathrm{X}$ ray showing free air in peritoneum. 
the air hose was "fired" through clothes at a distance from the anus [1-4].

Although the air pressure can vary in different situations, it takes only 1 or 2 seconds to deliver enough pressurized air to cause major damage. The rupture usually occurs in a longitudinal direction along the muscle fibers with full thickness perforation or with stripping of the serosa and muscularis. The most common injury location is the antimesenteric surface of the sigmoid colon [1]. Some patients may withhold information, trying to protect the guilty party or due to embarrassment. In such cases, the general symptoms are abdominal pain, abdominal distension, rectorrhagia, tachycardia, tachypnoea. Tension pneumoperitoneum is a characteristic presentation $[1,5,6]$. Death can depend on acute air embolism, acute fat embolism, acute respiratory insufficiency due to enhanced intra-abdominal pressure and chest compression, acute heart failure due to insufficient preload and peritoneal shock [5].

Percutaneous decompression of the tension pneumoperitoneum can be accomplished by inserting a cannula or a Veress needle into the abdomen for relief of the pressure [7]. Sixteen-gauge angiocath was inserted percutaneously in the right upper quadrant of the abdomen for decompression with alleviation of respiratory and hemodynamic problems [8]. The overall mortality of pneumatic rupture of the bowel was $65 \%$. If the acute shock was not immediately fatal, the survival was depending from further treatment. Surgery reduced mortality to $42 \%$ [9].

\section{Conclusion}

Compressed air related colorectal injuries are rare condi- tions admitted to emergency departments. Although taking history sometimes is not possible due to factors related with patients' condition, physical and radiological findings related with tension pneumoperitoneum can make physician diagnose injury and etiology.

\section{References}

1. Zunzunegui RG, Werner AM, Gamblin TC, Stephens JL, Ashley DW. Colorectal blowout from compressed air: case report. J Trauma. 2002;52(4):793-795.

2. Stone GW. Rupture of the bowel caused by compressed air. Lancet. 1904;2:216.

3. Andrews EW. Pneumatic rupture of the intestine: a new type of industrial accident surgery. Gynecol Obstet. 1911;12:63-64.

4. Suh HH, Kim YJ, Kim SK. Colorectal injury by compressed air--a report of 2 cases. J Korean Med Sci. 1996;11(2):179-182.

5. Weber M, Kolbus F, Dressler J, Lessig R. Survived ileocecal blowout from compressed air. Int J Legal Med. 2011;125(2):283-287.

6. Avallone S, La Torre M, Meurette G. Rectal injury by compressed air. J Trauma. 2010;68(1):248.

7. Millar DM. Tension pneumoperitoneum: a simple solution. Br J Hosp Med. 1988;40(2):149.

8. Chan SY, Kirsch CM, Jensen WA, Sherck J. Tension pneumoperitoneum. West J Med. 1996;165(1-2):61-64.

9. Brown RK, Dwinelle JH. Rupture of the Colon by Compressed Air: Report of Three Cases. Ann Surg. 1942;115(1):13-20. 